
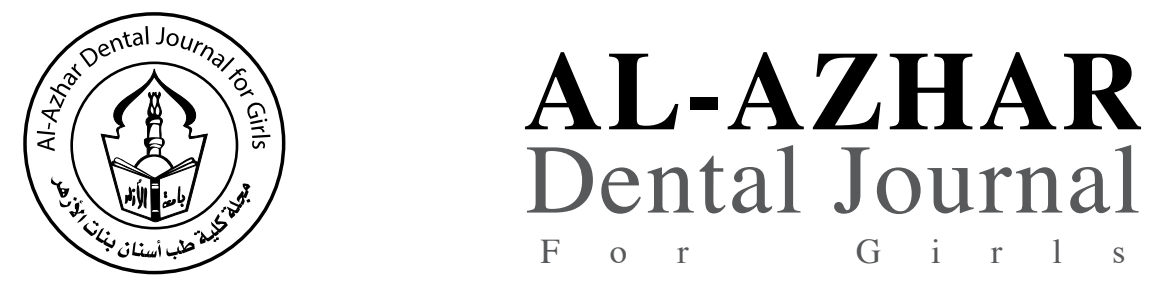

The Official Publication of The Faculty of Dental Medicine For Girls, Al-Azhar University Cairo, Egypt.

ADJ-for Grils, Vol. 4, No. 3, July (2017) — PP. 189:196

\title{
Effect of Nanostuctured Hydroxyapetite Incorporation into a Resin Composite on Shear Bond Strength to Dentin and Interfacial Micromorphology after Storage in Different Media
}

\author{
Mona R. Abo EI Wafa(1), Maha A. Niazy(2) and Heba E. EI Tayeb(2)
}

Codex : 22/1707

dentaljournal.forgirls@yahoo.com

\section{KEYWORDS}

Resin Composite,

Hydroxyapatite,

shear bond strength.

\begin{abstract}
Aim: This study was designed to evaluate the effect of incorporation of hydroxyapatite nanorods into a resin composite restorative material and dental adhesive on shear bond strength to dentin and interfacial micromorphology after storage in different media. Materials and Methods: Ninety natural premolars $(\mathrm{N}=90)$ were selected for this study and randomly divided into three main groups $(n=30)$ according to the material used (A), where A1: the resin composite restorative material reinforced with hydroxyapatite nanorods. A2: Adhesive resin material with incorporated hydroxyapatite nanorods, while A3: Resin composite (without nano-hydroxyapatite) as control group. Each group was subdivided into three subgroups $(n=10)$ according the storage media (B) either Acid (B1), artificial saliva (B2) or distilled Water (B3). All specimens were thermocycled then stored at room temperature and kept under each of the above mentioned media for 3 hours every day over 30 days (one month). All samples were individually and horizontally mounted on a Universal testing machine loaded to failure at cross head speed of $0.5 \mathrm{~mm} / \mathrm{min}$ then Shear bond strength was calculated. The fractured specimens were tested under scanning electron microscope to examine the dentin adhesive interface and mode of failure. Data were analyzed using one-way analysis of variance (ANOVA) and Tukey's post hoc significance difference tests. Differences were considered significant at $\mathrm{P}<0.05$. Results: There was a statistically significant difference between groups $(\mathrm{p} \leq 0.05)$. Adhesive resin with incorporated hydroxyapatite nanorods recorded statistically significant mean higher shear bond strength $(6.33 \pm 1.53,11.35 \pm 0.78$ and $7.97 \pm 0.57)$ after storage in (acid, artificial saliva, distilled water), followed by resin composite incorporates nanorods
\end{abstract}

Paper extracted from master thesis titled "Effect of Nanostuctured Hydroxyapetite Incorporation into a Resin Composite on Shear Bond Strength to Dentin and Interfacial Micromorphology after Storage in Different Media"

1. Dentist at ministry of health.

2. Professor and Head of Operative Dentistry Department, Faculty of Dental Medicine for Girls. Al-Azhar University.

3. Lecturer of Dental Biomaterials Department, Faculty of Dental Medicine for Girls, Al Azhar University. 
$(4.86 \pm 1.03,9.31 \pm 1.15$ and $6.85 \pm 0.95)$ and the least values were for control group $(3.11 \pm 1.02,7.3 \pm 1.55$ and $6.004 \pm 1.09)$. Tukey's post hoc test revealed a significant difference between each two subgroups. Conclusions: Incontrporating hydroxyapatite nanorods into the resin composite and adhesive resin greatly improves the shear bond strength to dentin after storage in different media regardless the type of the media and micromorphological observations correlates with the shear bond strength and failure mode.

\section{INTRODUCTION}

In the era of esthetic dentistry, resin based composites are the material of choice for most restorative procedures. Despite significant improvements, these materials still exhibit deficiencies that impair their longevity. Secondary caries and fracture have been reported as the main reasons for long term failure. Insufficient mechanical strength in loadbearing areas of posterior teeth, high polymerization shrinkage and shrinkage stress remain the key short-comings of resin based composites ${ }^{(1-3)}$.

Several efforts have been proposed to improve the mechanical and biological properties through improvements in the filler packing, optimizing of filler content, development of hybrid fillers. One of these fillers is hydroxyapatite which has been proposed as a filler for composite materials and was later introduced into adhesives at nanometer scale improving several of the material properties ${ }^{(4,5)}$.

With development of nanotechnology, a major impact on the material science has been noted. In this century, the production of materials with nanostructures has gained much attention for adsorption, catalytic, biomaterials and optical applications. Hydroxyapatite is the main biomineral found in the human hard tissues $\left(\mathrm{Ca}_{10}\left(\mathrm{PO}_{4}\right)_{6}(\mathrm{OH})\right)$. It is comprised of calcium and phosphorus present in the ratio $(\mathrm{Ca} / \mathrm{P})$ of $1.67^{(6)}$. Hydroxyapatite has attracted much interest as a biomaterial for use in prosthetic applications due to its similarity in crystallography and chemical composition to that of human hard tissue. On account of its outstanding properties like biocompatibility, bioactivity, osteoconductivity, non-toxicity and non-inflammatory nature which have a variety of applications that include bone tissue engineering, endodontic treatment, edentulous ridge augmentation, desensitizing agent post bleaching, treating early carious lesions, fillers for reinforcing restorative glass ionomer cement and restorative composite resin ${ }^{(7)}$. Addition of hydroxyapetite as a filler particle to resin composite was first reported in 1988 by Okazaki and Ohmae which results in improvement of mechanical properties and biocompatibility only when the apetite to resin ratio was maintained at $1^{(8)}$. Then later hydroxyapetite nanoparticles have been used in the formulation of restorative composite systems ${ }^{(9,10)}$. Moreover, they were used in dental adhesives to fortify the adhesive bond strength of adhesive to dentin ${ }^{(5)}$. Therefore, the present study aimed at evaluating the effect of incorporation of nano rod hydroxyapatite into a resin composite restorative material and a dental adhesive on shear bond strength to dentin after storage in different media (acid, artificial saliva and distilled water) Furthermore, interfacial micromorphology was also studied.

\section{MATERIALS AND METHODS}

\section{Preparation of samples:}

Non- carious ninety natural premolars in persons under the age of twenty- one years were collected, cleaned, scrubbed and scaled to remove blood, mucous, shreds of periodontal ligaments and calculus then stored refrigerated at $4^{\circ} \mathrm{C}$ in distilled water. The ninety teeth were divided into three main groups of 30 each $(n=30)$ according to the materials used (A), where A1: the resin composite restorative material reinforced with hydroxyapatite nanorods was applied over the bonded surfaces. A2: Adhesive resin material with incorporated hydroxyapatite nanorods was used over dentin surfaces, while A3: Composite resin restorative material (without nanohydroxyapatite) was used over the bonded dentin surfaces as control group. Each group was further subdivided into three subgroups of 10 each $(n=10)$ according the storage media (B) either Acid (B1), artificial saliva (B2) or distilled water (B3). 
Each tooth was embedded in self cured acrylic resin block which was fabricated by using a plastic mold with dimensions of $1.6 \mathrm{~cm}$ diameter and $2 \mathrm{~cm}$ height on to which chemically activated acrylic resin (Acrostone ,Manufacturing and Import Co.,Egypt) was packed. The long axis of the teeth was adjusted parallel to that of the plastic ring using parallometer (AF3O,Nouvag. Switzerland). Occlusal surfaces were made flat with double-faced diamond disc by cutting the occlusal surface through a mark made about $3 \mathrm{~mm}$ apical to the cusp tips under water cooling until a clean dentinal surface was exposed. The prepared dentin surfaces were then be polished with $180,320,600$ grit wet silicon carbide paper to stimulate the production of smear layer. All the prepared specimens were then stored for 24 hours in incubator at $37^{\circ} \mathrm{C}$.

\section{Bonding Procedures:}

The prepared dentin surface was etched using $37 \%$ phosphoric acid gel for 15 seconds then thoroughly rinsed with water for 15 seconds and excess water was gently blotted dry with the help of cotton pellets. For group (A1, A3) the bonding procedures were done following the manufacture's instructions by applying two coats of Tetric N-bond (Ivoclar Viva dent) by the help of a fully saturated disposable brush tip, gently dried for 2-5 seconds with air blast and light cured for 10 seconds each using LED unit (Cordless LED curing light system, TPC Advanced Technology, city of industry 91748 USA).For group (A2) the modified adhesive( Tetric-N bond) was shacked well, 2 consecutive coats of the adhesive were applied for 20 seconds with gentle agitation using a brush, gently air thinned with air for 5 seconds to evaporate solvents and light cured for 20 seconds.

\section{Resin Composite build up:}

For group (A1)Te-Econom Plus resin composite (Ivoclar,Viva dent shade A1) incorporates hydroxyapatite nanorods and for groups (A2, A3) Te-Econom plus resin composite without hydroxyapatite nanorods was dispensed and packed in one increment (bulk packing) using a plastic instrument (Noredent Basic Composite Kit, Norden, Germany) on the dentin surface held in position by the split Teflon mold of dimensions $(4 \mathrm{~mm}$ in diameter $\times 2 \mathrm{~mm}$ in thickness) then plastic matrix strip (Greko Grgor.Kostunov, 69124, Germany) was placed over the resin composite and gently pressed flat with a glass slap and the excess resin composite was removed by a sharp instrument. After removal of the glass slap, the resin composite was light cured for 20 seconds using LED curing device then the Teflon mold was removed.

\section{Thermocycling:}

All specimens were subjected to thermocycling procedures in thermocycling apparatus (ROBOTA automated thermo-cycle; BILGE, Turkey ) the number of cycles used were 500 cycles and dwell time was 25 seconds in each water bath with a lag time 10 seconds. The low- temperature point was $5^{\circ} \mathrm{C}$ and the high- temperature point was $55^{\circ} \mathrm{C}$ corresponding to 6 months clinical use.

\section{Storage:}

All specimens were stored in different storage media for one month. These media include acid $0.01 \mathrm{M}$ Lactic acid buffer solution of $\mathrm{pH} 4$, artificial saliva ( $\mathrm{pH}$ value $6.75 \pm 0.15$ ) and distilled water (Pure water $\mathrm{H} 2 \mathrm{O}$ of neutral $\mathrm{pH}$ ).

\section{Shear bond strength test:}

After all groups were stored for one month, the specimens were removed from the test solutions and thoroughly cleaned, dried and then subjected to shear bond test which was done using Universal testing machine at cross head speed of $0.5 \mathrm{~mm} / \mathrm{min}$.

\section{Scanning electron microscope testing:}

The fractured specimens were tested under Scanning Electron Microscope to examine the dentin adhesive interface and mode of failure using Quanta 250 FEG (Field emission Gun) attached with EDX unit (Energy Dispersive X-ray analysis with accelerating voltage $30 \mathrm{kv}$ ). 


\section{Statistical Analysis:}

Values of shear bond strength were presented as mean and standard deviation (SD) values. (One way analysis of variance ANOVA test) was used to compare between groups and sub-groups. Two ways analysis of variance ANOVA test was used to study the statistical significance of the interaction between variables (material used and storage medium).

\section{RESULTS}

\section{I- Hydroxyapetite nanoparticles characterization results:}

The resultant Transmisson Electron Microscope (TEM) micrographs showed that the prepared hydroxyapetite nanorods had size ranging between $20-100 \mathrm{~nm}$ in diameter and 10-20 nm in length with slight tendency to agglomerate. Photomicrographs of the modified adhesive system and resin composite confirmed the uniform distribution of the nanorods with tendency to aggregate.

\section{II-Shear bond strength results:}

There was a statistically significant difference between groups $(\mathrm{p} \leq 0.05)$. On using acids as storage medium, the greatest mean shear bond strength $(6.33 \pm 1.53)$ was recorded for (group A2) followed by (group A1) $(4.86 \pm 1.03)$, and the least value was for control group $(3.11 \pm 1.02)$. On using artificial saliva as storage medium, the greatest mean shear bond strength $(11.35 \pm 0.78)$ was recorded for (group A2), followed by (group A1) $(9.31 \pm 1.15)$, and the least value was for control group $(7.3 \pm 1.55)$ Tukey's post hoc test revealed a significant difference between each two groups and finally on using distilled water as a storage medium the greatest mean shear bond strength $(7.97 \pm 0.57)$ was recorded for (group A2), followed by (group A1) $(6.85 \pm 0.95)$, and the least value was for control group $(6.004 \pm 1.09)$ Tukey's post hoc test revealed no significant difference between group A1 and A3 (control). Two ways ANOVA test was used to test interaction between variables and revealed a significant difference between materials used (rows) $(\mathrm{p} \leq 0.05)$, as well as a significant difference between storage media (columns), $(\mathrm{P} \leq 0.05)$. However, the interaction between both variables (material used and storage media) was not statistically significant $(\mathrm{p}>0.05)$ Values are presented numerically in table (1).

\begin{tabular}{|c|c|c|c|c|c|c|}
\hline \multirow{2}{*}{\multicolumn{2}{|c|}{ Shear Bond Strength (MPa) }} & \multirow{3}{*}{$\begin{array}{c}\begin{array}{c}\text { B1 } \\
\text { (acids) }\end{array} \\
4.86^{\mathrm{cB}}\end{array}$} & \multirow{3}{*}{$\begin{array}{c}\mathbf{B 2} \\
\text { (artificial saliva) }\end{array}$} & \multirow{3}{*}{$\begin{array}{c}\text { B3 } \\
\text { (Distilled water) } \\
6.84^{\mathrm{bB}}\end{array}$} & \multicolumn{2}{|c|}{ (material used) } \\
\hline & & & & & $\Gamma$ & \\
\hline \multirow{2}{*}{ Group A1 } & Mean & & & & \multirow{8}{*}{57.13} & \multirow{8}{*}{$<0.0001 *$} \\
\hline & SD & 1.03 & 1.15 & 0.95 & & \\
\hline \multirow{2}{*}{ Group A2 } & Mean & $6.33^{\mathrm{cA}}$ & $11.35^{\mathrm{aA}}$ & $7.97^{\mathrm{bA}}$ & & \\
\hline & SD & 1.53 & 0.78 & 0.57 & & \\
\hline \multirow{2}{*}{ Group A3 } & Mean & $3.11^{\mathrm{bC}}$ & $7.3^{\mathrm{aC}}$ & $6.004^{\mathrm{aB}}$ & & \\
\hline & SD & 1.02 & 1.55 & 1.09 & & \\
\hline \multirow{2}{*}{ (storage media) } & $\mathbf{F}$ & \multicolumn{3}{|c|}{125.09} & & \\
\hline & $P$ value & \multicolumn{3}{|c|}{$<0.0001^{*}$} & & \\
\hline \multirow{2}{*}{$\begin{array}{c}\text { Interaction between } \\
\text { variables }\end{array}$} & $\mathbf{F}$ & \multicolumn{5}{|c|}{2.27} \\
\hline & $P$ value & \multicolumn{5}{|c|}{$0.0687^{\mathrm{ns}}$} \\
\hline
\end{tabular}

*significant, $n s=$ non-significant at $p<0.05$

Mean values with different small letters are significantly different within the same row.

Mean values with different capital letters are significantly different within the same column. 


\section{III- Failure mode results:}

After shear bond strength test, all the failed specimens were examined using USB digital microscope at 50X magnification to determine the nature of their fracture. Failure type was noted as adhesive, cohesive in resin composite, cohesive in dentin or mixed.
Evaluation of failure modes after shear testing indicated that high bond strength groups showed mixed or cohesive modes, while low bond strength groups tended to exhibit adhesive failure mode. Statistical analysis was performed by using Chi square test to study effect of different materials within each storage media on failure mode numerical values are presented numerically table (2).

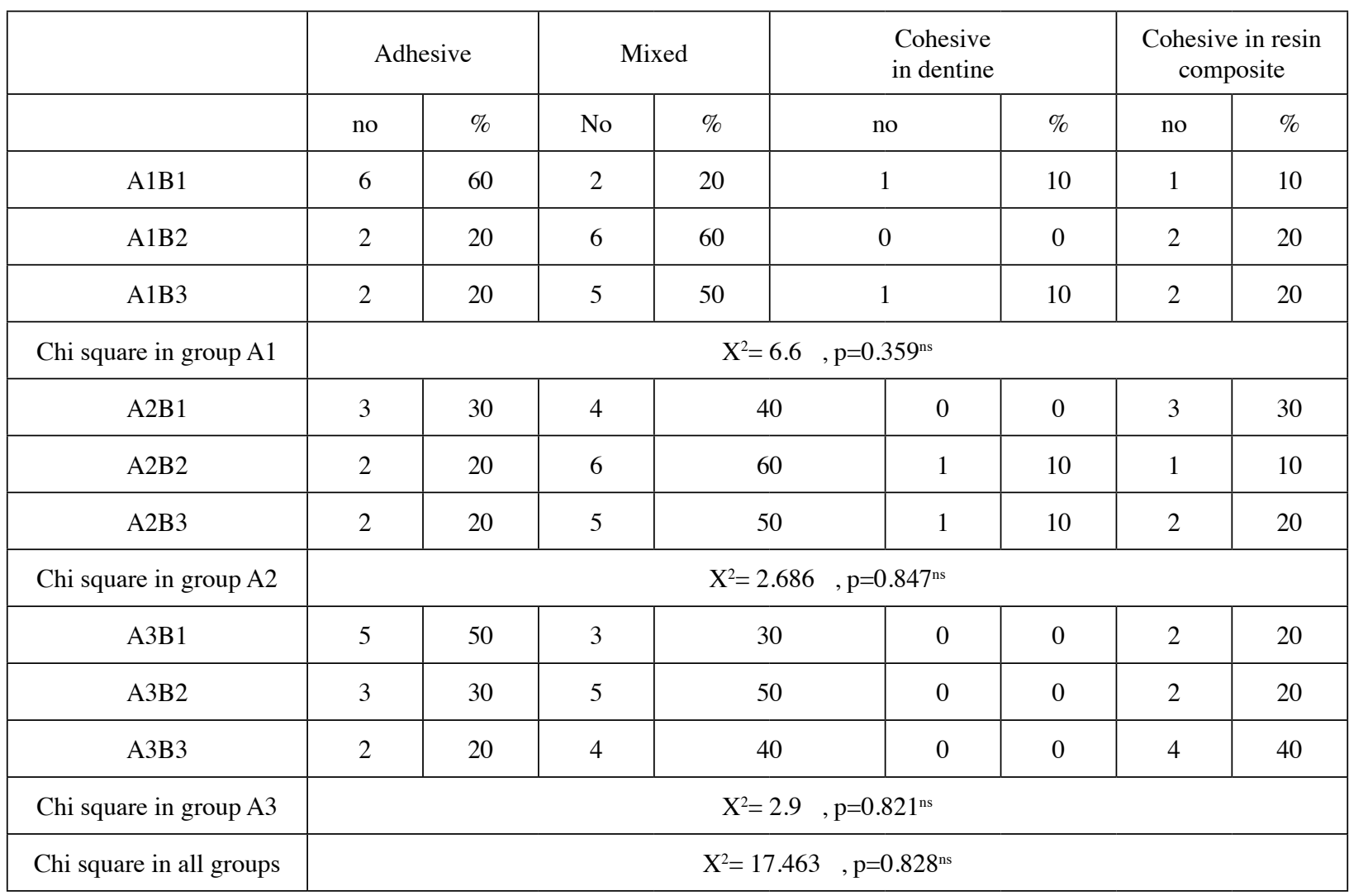

\section{DISCUSSION}

The clinical performance of composite restorations depends in part upon complete adhesion of the restorative composites to enamel and dentin. For enamel, the acid-etch procedure is usually successfully used ${ }^{(11,12)}$. Moreover, oral cavity is a complex environment, where the restorative material is in contact with saliva which contains a variety of inorganic and organic species together with bacterial flora. ${ }^{(13)}$ Furthermore, $\mathrm{PH}$ changes and thermal cycling from changes in oral temperature provide conditions for degraded bond strength in an aqueous environment ${ }^{(14)}$.

Recently, nanoparticles as hydroxyapatite have been used in the formulation of restorative composite systems with the aim of improving physical and mechanical properties, bioactivity and bond strength of these resin composites to dental structures and have also been incorporated into the dental adhesives ${ }^{(5)}$. The present study was designed to evaluate the effect of incorporation of hydroxyapatite nanorods into a resin composite 
restorative material and a dental adhesive on shear bond strength to dentin after storage in different media (acid, artificial saliva and distilled water).

The results obtained in this study showed that shear bond strength mean values of (Resin composite incorporates hydroxyapatite nanorods) showed a higher statistically significant difference compared to (Resin composite without HA nano rods) when stored in lactic acid (B1) and artificial saliva (B2). This could be attributed to the incorporation of HA nano rods into the resin composite which increased the filler loading that reduces the polymerization shrinkage, water sorption of the resins, thermal expansion coefficient and improve the mechanical strength properties which may in turn improve the bond strength to dentin ${ }^{(15,16)}$.

The increase in the mixed mode of failure at the resin / adhesive interface within resin composite incorporates HA nanorods group (A1) may indicate the strengthening effect and improvement of bond strength. This is in agreement with many studies ${ }^{(17-19)}$. Moreover, these findings are supported by SEM photomicrograph observations which showed thick well formed hybrid layer with numerous resin tags extending into the widely opened dentinal tubules while SEM photomicrographs of group (A3) showed a thin non homogenous hybrid layer and few, weak and faint resin tags extending into the widely opened dentinal tubules and adhesive mode of failure.

Regarding the shear bond strength mean values of adhesive resin incorporates HA nanorods showed the highest statistically significant difference compared to resin composite incorporates HA nanorods) and control group after storage in acid (B1), artificial saliva (B2) and distilled water (B3). This could be attributed to addition of fillers into the adhesive resin that resulted in increase adhesion to the tooth substrate and decrease degradation of the material over time ${ }^{(20,21)}$. Also, HA fillers may improve adhesive mechanical properties by strengthening the adhesive layer; prevent thinning of adhesive layer providing better relief of composite contraction stresses $^{(22)}$. HA fillers have been shown to increase polymerization rate and degree of conversion thus diminishing polymerization shrinkage and increasing the modulus of elasticity of the adhesive layer which may results in increasing bond strength to enamel and dentin ${ }^{(23)}$. This result was in agreement with many studies ${ }^{(5,24,25)}$.

The shear bond strength results of different subgroups were obviously related to the storage media used in each subgroup. Within resin composite with HA nanorods, Adhesive resin incorporates HA and control group, subgroups stored in lactic acid (B1) had the lowest (SBS) mean and SD values and showed a significant difference compared to those stored in artificial saliva (B2) and distilled water (B3) This could be attributed to detrimental effects of acid on the resin based composites; the fillers tend to fall out from the resin material (26), matrix components decomposed when exposed to low $\mathrm{PH}$ environment ${ }^{(27)}$ and the resin based composites were found to undergo greater micromorphological damage. In oral environment, the effect of acids and other solvents may have detrimental and sustained effect on the mechanical properties of resin composites ${ }^{(28)}$.

As for the shear bond strength mean values of subgroups stored in artificial saliva (B2) within group A1 and group A2 showed a high significant difference compared to those stored in lactic acid (B1) and distilled water (B3).This could be attributed to the fact that the artificial saliva contains many minerals like $\mathrm{Ca}^{++}, \mathrm{PO}_{4}^{--}, \mathrm{Na}^{+}$and urea during storage, deposition of these minerals on the surface of the resin composite resulted in the formation of film probably composed of calcium on the surface of resin composite increasing the mechanical properties of resin composite ${ }^{(29)}$. The results were in agreement with ${ }^{(30,31)}$ who measured the micro hardness of the resin composite after conditioning in saliva and orange juice and the results showed that the micro hardness increased after storage in artificial saliva. 
The shear bond strength mean values of subgroups stored in distilled water (B3) within group A1, group A2 and control group showed a higher significant difference compared to those stored in lactic acid (B1) but in the same time showing a lower shear bond strength values than those stored in artificial saliva (B2). This could be attributed to the fact that on immersion of resin composite in water two processes took place; first, swelling of the resin composite and second, leakage of unreacted monomers and dissolution of resin composite owing to hydrolytic degradation ${ }^{(18)}$. The results were in agreement with ${ }^{(32,33,34)}$ who suggested that water sorption into the demineralized dentin might cause hydrolytic degradation of the collagen fibrils at this zone leading to decrease in bond strength.

\section{CONCLUSIONS}

Within the limitations of this study, the following could be concluded:

1. Incontrporating $1 \mathrm{wt} \%$ Hydroxyapatiten norods into the resin composite (Te-Econom Plus) had greatly improved the shear bond strength to dentin after storage in different media regardless the type of the media used in the study.

2. Modifying the adhesive system (Tetric $-\mathrm{N}$ bond) by $2 \mathrm{wt} \%$ hydroxyapatite nanorods provided a superior improvement in shear bond strength of the resin composite to dentin and produced adhesive system that is less prone to degradation.

3. Micromorphological observations at the interface between resin composite and dentin correlates with the shear bond strength and the failure mode.

\section{REFERENCES}

1. Brunthaler A, Konig F, Lucas T, Sperr W, Schedle A .Longevity of dental resin composite restorations in posterior teeth. Clin Oral Invest 2003;7:63 -70.

2. Demarco FF, Correea MB, Cenci MS, Moraes RR, Opdam NJ. Longevity of posterior composite restoration: Not only a matter of material. Dent mater 2012; 28:87-101.
3. Sarrett DC. Clinical challenges and the relevance of materials testing for posterior composite restorations. Dent Mater 2005; 21:9-20.

4. Labella R, Barden M, Deb S. Novel Hydroxyapatite based dental composites. Biomat 1994;15:1197-200.

5. Sadat-Shojai M, Atai M, Nodehi A, Khanlar LN. Hydroxyapatite nanorods as a Novel fillers for improving the properties of Dental Adhesives; Synthesis and Application. Dent Mater 2010;26:471-82.

6. Oliveira M, Mansur HS. Synthetic tooth enamel: SEM Characterization of fluoride hydroxyapatite coating for dentistry applications. Mater Res 2007;10:115-8.

7. Kantharia N, Nalik S, Apte S, Kheur M, Kale B. Nanohydroxyapatite \& its Contemporary application. J Dent Res Sci Dev 2014:1(1):15-9.

8. Okazaki M, Ohmae H. Mechanical and Biological Properties of apatite Composite resins. Biomat 1988; 9:345-8.

9. Mitra BS, Wu D, Holmes NB. An application of nanotechnology in advanced dental materials. J A D A 2003;134:1382-90.

10. Moszner N. and Salz U. Recent developments of new components for dental adhesives and composites. Macr Mater Engin 2007;292(3):245-71.

11. Hashimoto M, Ohno H, Sano H, Tay FR, Kaga M, Kudoi Y, Oguchi H, Araki Y, Kuboto M. Micromorphological changes in resin-dentin bonds after 1 year of water storage. Biomed Mater Res J 2002; 36: 306-11.

12. Munck J, Van de Meerbeek B, Yoshida Y, Inoue S, Vargas M, Suzuki K, Lambrechts P, Vanherle G. Four-year water degradation of total-etch adhesives bonded to dentin. Dent Res J 2003; 82: 136-40.

13. Okada K, Tosaki S, Hirota K, Hume WR. Surface hardness change of restorative filling materials stored in saliva. Dent Mater 2001;17:34- 9.

14. Xu HH, Eichmiller FC, Smith DT, Schumacher GE, Gluseppetti AA, Antonucci JM. Effect of thermal cycling on whisker- reinforced dental resin composites. J mater sci mater med.2002;13:875-83.

15. Schulze K.A, Zaman A.A, So“derholm K J.M. Effect of filler fraction on strength, viscosity and porosity of experimental compomer materials. J Dent 2003; 31:373-82.

16. Shan P.K, Stansbury J.W. Role of filler and functional group conversion in the evolution of properties in polymeric dental restoratives. Dent Mater 2014;30: 586-93. 
17. Lezaja M, Veljovic D N, Jokic B. M, Cvijovic-Alagic I, Zrilic M. M. ,Miletic V. .Effect of hydroxyapatite spheres, whiskers, and nanoparticles on mechanical properties of a model BisGMA/ TEGDMA composite initially and storage. J Biomed Mater Res 2013;101(8):1469-76.

18. Christie Ying Kei Lung, Zenab Sarfraz, Amir Habib, Abdul Samad Khan, Jukka Pekka Matinlinna. Effect of silanization of Hydroxyapatite fillers on physical and mechanical properties of Bis-GMA based resin composite. J mech beha biomed mater 2016;283-94.

19. Santos C, Luklinska ZB, Clarke RL, Davy KW. Hydroxyapatite as filler for dental composite materials: Mechanical properties and invitro bioactivity of composites. J Mater Sci: Mater Med 2001;12:565-73.

20. Van Landuyt KL, Snauwaert J, De Munck J, Peumans M, Yoshida Y, poitevin A, et al. Systemic review of the chemical composition of contemporary dental adhesives. Biomater 2007;28:3757-85.

21. Kalachandra S. Influence of fillers on the water sorption of composites. Dent Mater 1989;5:283-8.

22. Miyazaki M, Ando S, Hinoura K, et al. Influence of filler addition to bonding agents on shear bond strength to bovine dentin. Dent Mater 1995;11:234-8.

23. Zhang Y, Wang Y. Effect of Hydroxyapatite presence on the degree of conversion and polymerization rate in a model self-etching adhesive. Dent Mater 2012;28:237-44

24. Dumont VC, Silva RM, Almeida-JÚnjar LE, Roa JPB, Botelho AM, Santos MH. Characterization \& evaluation of bond strength of dental polymer systems modified with hydroxyapatite nanoparticles. J Mater Sci Chem Engin 2013;1:13-23

25. Leitune V.C., Collares F.M., Trommer R.M., Andrioli D.G., Bergmann C.P, Samuel S.M. The addition of nanostructured hyroxyapatite to an experimental adhesive. J Dent 2013; 41:321-7.

26. Neamat AB, Han L, Okamato A, Iwaku M. Effect of alcoholic and low $\mathrm{PH}$ soft drinks on fluoride release from compomer. J Eth Res Dent 2000;12:97-104.

27. Kitchens M, Owens BM. Effect of carbonated beverages, Coffee, Sports \& high energy drinks \& bottled water on the in-vitro erosion characteristic of dental enamel. J Clin Ped Dent 2007;31:153-9.

28. Yesilyurt C, Yoldas O, Altintas SH, Kusgoz A. Effects of food simulating liquids on the mechanical properties of silorane based dental composite. J Dent Mater 2009; 28:362-7.

29. Al Wahab ZN. An evaluation of the effect of different solutions on the microhardness of aesthetic restoration. M D J 2011;8:106-14.

30. Mckenzie AM, Linden RWA, Nicholson JW. The effect of coca-cola \& fruit juices on the surface hardness of glassionomers and compomers. J Oral Rehab 2004;31:1046-52.

31. Martins de Oliveira ALB, Gracia PPNS, Alexio dos Santos $\mathrm{P}$, Campos JADB. Surface roughness and hardness of a composite resin. Influnce of finishing and polishing \& immersion method. Mater Res J 2010;13:409-15.

32. Nakabayashi N, Takarada K. Effect of HEMA on bonding to dentin. Dent Mater 1992;8:125-130.

33. Burrow MF, Satoh M, Tagami J. Dentin bond durability after 3 years using a dentin bonding agents with \& without priming. Dent Mater 1996;12:302-7.

34. Sano H, Yoshikawa T, Pereiru PNR, Kanemura N, Tagami J, Pashley DH. Long term durability of dentin bonds made with self-etching primer, Ivivo. J Dent Res 1999; 78:906-11. 